\title{
Bark Beetles, Fuels, Fire Potential and Nitrogen Cycling in Contrasting Conifer Forests of Greater Yellowstone
}

\section{Authors}

Monica G. Turner, Jacob M. Griffin, Philip A. Townsend, Martin Simard, Brian J. Harvey, Daniel C. Donato, and William H. Romme 


\section{Bark Beetles, Fuels, Fire Potential and Nitrogen Cycling in ConTrasting Conifer FORESTS OF GREATER YELLOWSTONE}

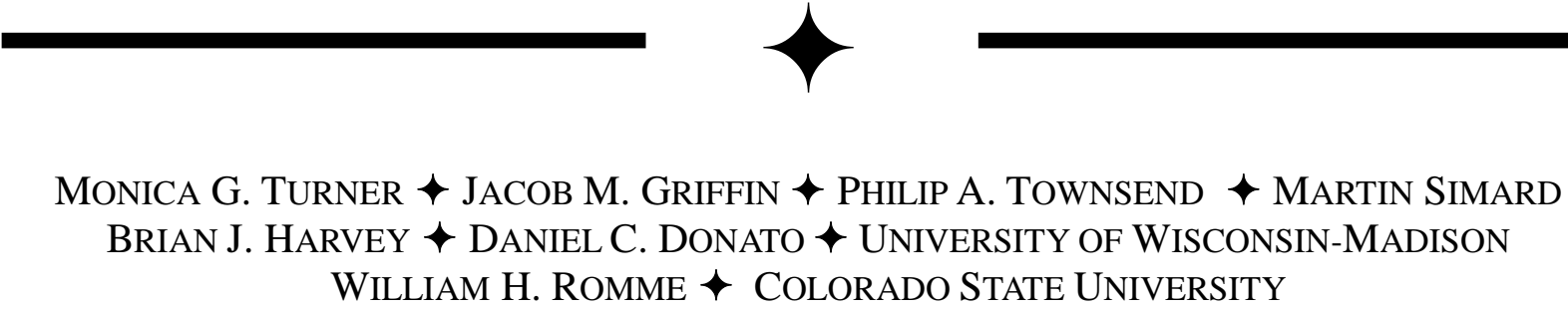

\section{$\uparrow \quad$ Abstract}

Recent increases in insect and fire activity throughout the western US have presented forest managers with formidable challenges. The extent and severity of bark beetle (Curculionidae: Scolytinae) epidemics have reached unprecedented levels, and the number of large, severe fires continues to increase. These trends are expected to continue because climate change is implicated for both disturbances. Insects and fire have tremendous ecological and economic effects in western forests, yet surprisingly little is known about how fire hazard may change following bark beetle epidemics, and the efficacy of alternative forest management practices (e.g., removal of beetle-killed trees or remaining small trees) designed to reduce future fire hazard is largely unknown. We are employing a combination of field studies, remote sensing and simulation modeling to understand how bark beetle infestation affects fire hazard in two widespread but contrasting forest types, lodgepole pine (Pinus contorta) and Douglasfir (Pseudotsuga menziesii). Lodgepole pine and Douglas-fir forests are key components of Rocky Mountain landscapes, and both are experiencing extensive and severe bark beetle outbreaks. Published research on beetle effects on fire in lodgepole pine forests is inconclusive, and almost no studies have examined Douglas-fir. We hypothesize that differences in fire regime, stand structure, regeneration potential and decomposition of woody fuels lead to important differences in fuel profiles, fire hazard and, in turn, the effectiveness of alternative mitigation strategies in lodgepole pine and Douglas-fir. We also anticipate that ecosystem responses, especially nitrogen cycling, to beetle attack will differ between these two forest types. Our studies are being conducted in Grand Teton and Yellowstone National Parks, and the Bridger-Teton and Shoshone National Forests within the Greater Yellowstone Ecosystem (GYE), where we build on $>20$ years of research and our recent studies of bark beetles and fire in lodgepole pine forests. During the summer of 2010, we conducted a significant portion of the field component of the project, measuring stand structure and fuel profiles in a chronosequence of Douglas-fir forests of differing time since beetle attack (TSB), and also measuring burn severity and forest regeneration following a 2008 fire that burned a recently beetle-attacked forest. Data analyses are ongoing and results will be forthcoming.

\section{$\uparrow \quad$ INTRODUCTION}

Recent increases in insect and fire activity throughout the western US have presented forest managers with formidable challenges. The extent and severity of bark beetle (Curculionidae: Scolytinae) epidemics have reached unprecedented levels (Raffa et al. 2008), and the frequency of large, severe fires continues to increase (Westerling et al. 2006). These trends are expected to continue because climate change-especially warmer temperatures, earlier snowmelt and more severe summer droughts-is implicated for both disturbances. Insects and fire have tremendous ecological and economic effects in western forests, yet their interaction is poorly understood. Surprisingly little is known about how fire hazard may change following bark beetle 
epidemics, and the efficacy of forest management practices (e.g., removal of beetle-killed trees or remaining small trees) designed to reduce future fire hazard is largely unknown. Scientists have begun tackling these problems (e.g., Jenkins et al. 2008), but empirical data are scarce (see annotated bibliography at http://www.fs.fed.us/wwetac/publications.html by Simard et al. 2008). Research has shown that time since beetle outbreak is critical for understanding the relationship between beetle outbreaks, stand structure, fuel dynamics and fire hazard, but again, empirical data are few. We are employing a powerful combination of field studies, remote sensing and simulation modeling to understand how bark beetle infestation and post-outbreak management affect fire hazard in two widespread but contrasting forest types, lodgepole pine (Pinus contorta) and Douglasfir (Pseudotsuga menziesii). Published research on beetle effects on fire in lodgepole pine forests is inconclusive, and very few studies have examined Douglas-fir. Our studies are being conducted in Grand Teton and Yellowstone National Parks, and the Bridger-Teton and Shoshone National Forests within the Greater Yellowstone Ecosystem (GYE), where we build on $>20$ years of research and our recent studies of bark beetles and fire in lodgepole pine forests.

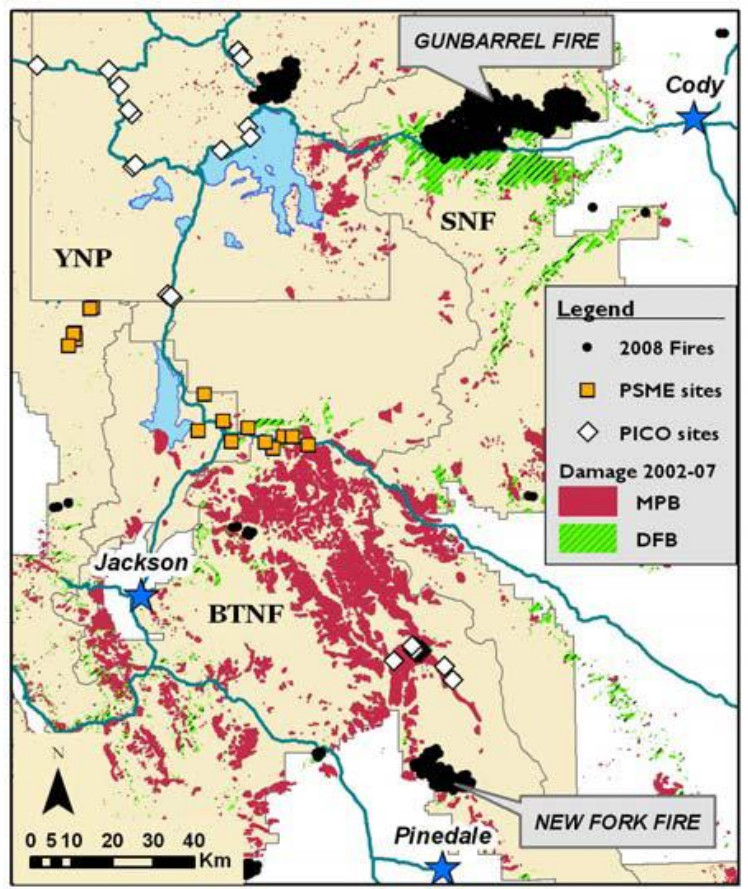

Figure 1. Study sites are located across much of Greater Yellowstone. Fire severity is being sampled in two recent fires, along with remote sensing. The New Fork Fire was sampled in the summer of 2010. A time-since-beetle chronosequence of Douglas-fir stands was also sampled in 2010, which will be compared to our existing chronosequence in lodgepole pine stands
Lodgepole pine and Douglas-fir forests are key components of Rocky Mountain landscapes. Both are experiencing extensive and severe bark beetle outbreaks, yet important differences between these forest types (Keane 2008) suggest that postbeetle changes in fuel hazard may be distinct. We hypothesize that differences in fire regime, stand structure and regeneration potential lead to important differences in fuel profiles and fire hazard in lodgepole pine and Douglas-fir. We are focusing on changes in fuel profiles over time and the effects of insect outbreak on fire behavior (both recent and future). In addition, the consequences of bark beetles on ecosystem processes, especially nitrogen (N) cycling, may also differ between these two forest types. Although effects of bark beetles on stand have been well studied, the consequences of bark beetle outbreaks for nitrogen $(\mathrm{N})$ cycling have not been widely studied. Collectively, we are directly addressing key bark beetle research priorities identified by US Forest Service scientists for the western US (Negron et al. 2008).

\section{Project Objectives and Hypotheses}

Question 1: How do effects of bark beetle outbreaks on fuel profiles and subsequent fire hazard differ between lodgepole pine and Douglas-fir forests? Bark beetle outbreaks substantially alter stand structure and live and dead fuel characteristics. We are beginning to understand how fuels and potential fire behavior change over time following mountain pine beetle outbreaks in lodgepole pine forests, based on data from our current research (Simard et al., 2011) and similar studies (Lynch et al. 2006; Page and Jenkins 2007a, 2007b; Jenkins et al. 2008). Major trends include an initial (3-5 yr postoutbreak) reduction in canopy bulk density and continuity, as dead needles fall from beetle-killed trees; and a later (20 yr post-outbreak) increase in large dead woody fuels as dead trees fall. Live herbaceous fuels may increase after the canopy is opened, and surviving trees (mostly understory individuals) may grow into the canopy after $20 \mathrm{yr}$, increasing ladder fuels. Studies in Utah and Idaho (Page and Jenkins 2007a, 2007b, Jenkins et al. 2008) found increased fine fuel loads that increased flame length early after beetle outbreak. Our data for lodgepole pine in the GYE indicate that the likelihood of active crown fire is reduced following beetle outbreak (Simard et al. 2011). Further, little research has addressed interior Douglas-fir forests, which are extensive in the Rockies and often coincide with locations where residential development is increasing. Given differences in structure and dynamics of lodgepole pine and Douglas-fir forests, 
we anticipate significant differences in post-beetle fuel dynamics and potential fire behavior, and our studies are underway.

Question 2: How was the severity of recent fire in lodgepole pine and Douglas-fir forests affected by prior bark beetle infestation, and does the combination of beetle infestation and fire compromise forest recovery? The ability to address directly the effects of beetle infestation on fire severity has been limited by a lack of spatially explicit data to characterize the extent and severity of both disturbances and an absence of field studies of fire in beetle-killed forests. Because the likelihood and severity of fire is affected by the timing of beetle infestation and may vary with forest type, there is a need to characterize the landscape heterogeneity of fuels created by bark beetle infestation in both space and time. Recent advances in remote sensing of forest ecosystems has led to the development of methods to accurately map both fire severity (e.g., Miller and Thode 2007) and the extent (e.g., Wulder et al. 2006) and severity (Simard et al. in prep) of bark beetle damage at broad scales. These advances provide the opportunity to test whether recent beetle damage has contributed to more severe fires in beetle-damaged areas, and these studies are underway.

Question 3: How do bark beetles affect nitrogen cycling in lodgepole pine forests? Much research has addressed the effects of folivorous insects on forest ecosystems, but few studies have addressed the consequences of phloem feeders. Specifically, we asked how litter quantity and quality, soil nitrogen pool and fluxes, and foliar nitrogen varied with time-since-beetle outbreak. Beetleinduced litterfall has the potential to change both biotic and abiotic interactions in the litter-soil profile (Morehouse et al. 2008). Subsequent effects of these changes on soil $\mathrm{N}$ availability could allow greater uptake of $\mathrm{N}$ in unattacked surviving vegetation (Huber 2005). Substantial increases in soil N pools, particularly the ion $\mathrm{NO}_{3}{ }^{-}$, may indicate the potential for ecosystem loss of $\mathrm{N}$ via soil leaching (Huber 2005).

\section{STUDY AREA}

Our study is being conducted within the GYE in northwestern Wyoming (Figure1), including Yellowstone (YNP) and Grand Teton National Parks and the Bridger-Teton (BTNF) and Shoshone (SNF) National Forests. The mountain pine beetle (MPB) and Douglas-fir beetle (DFB) have both been active since 2002 in lodgepole pine and Douglas-fir, respectively, and in addition to the well-known 1988 fires, significant area has also burned recently. All work is being conducted under permits with both the national parks and national forests.

\section{$\uparrow \quad$ METHODS}

To contrast fuel profiles and fire hazard between the two forest types (Question 1), a "timesince-beetle" (TSB) chronosequence was sampled in Douglas-fir forests of the GYE to quantify fuel profiles from 0 to $20 \mathrm{yrs}$ since the epidemic. We completed this sampling during the summer of 2010. Results are being compared to our existing data for lodgepole pine. We are developing remote sensing products to map the variation in canopy, herbaceous and woody fuels in post-beetle stands across the GYE with TSB in both forest types. To determine how the behavior and severity of recent fires (2008) were affected by the bark beetle infestation (Question 2), field studies and remote sensing are being used to determine how actual spatial variation of fire severity across the landscape was related to pre-fire beetle infestation. A portion of the field sampling was completed during summer 2010. To evaluate the effects of bark beetles on $\mathrm{N}$ cycling (Question 3), empirical studies were conducted in the lodgepole pine TSB chronosequence during 2007-2008, and data analyses were completed during 2010.

\section{Field Measurements, Remote Sensing and Modeling}

Question 1. We are expanding our current field studies of post-beetle fuel loading in lodgepole pine (Figure 1) to Douglas-fir by establishing a similar TSB chronosequence of plots. Undamaged and gray Douglas-fir plots (2004-2005 outbreak) established in 2008 for nutrient cycling studies have been expanded to include fuels sampling (Figure 1), and new sites representing red attacks and 20 -yr old outbreaks have also been established). As in our lodgepole pine study, we sampled five replicates of each damage class (total $n=20$ plots). In each 0.25 -ha plot, we are quantifying the tree (DBH or height if $<1.4 \mathrm{~m}$ tall; live / dead; quantity of red needles; presence / absence beetle galleries and pitch tubes; crown base height); and understory (\% cover and height in twenty $1-\mathrm{m}^{2}$ quadrats) layers. Surface fuels were sampled in ten 20-m transects using Brown's planar intercept method (Brown 1974). We will then use our surface and canopy fuels data and NEXUS or similar models (Scott and Reinhardt 2001) to estimate potential fire behavior in our plots. We are producing vertical profiles of canopy bulk density for each plot, using field-measured crown base height, and crown fuel biomass estimated from $\mathrm{DBH}$ and allometric relationships (Brown 1978). We are using these 
profiles to derive effective canopy bulk density and canopy base height following Scott and Reinhardt (2001). Output fire behavior parameters will include predicted fire type (surface, active crown, passive crown, or conditional fire), surface fire activity (rate of spread, fireline intensity, etc.), torching index, and crowning index. Instead of using fixed fire weather conditions for the simulations (e.g., 97th percentile), we will identify weather conditions under which certain fire behavior thresholds are crossed. E.g., under which surface fuel moisture and 20-ft wind speed values do torching or crowning occur? This approach eliminates the constraint of having to rely on specific observed or projected weather scenarios.

Remote sensing using multispectral sensors such as Landsat generally does not provide the capacity to measure surface and canopy fuel loads directly (although see Keane et al. 2006). However, these properties of disturbed forests can be inferred with a fairly high accuracy from the measures of forest mortality associated with a specific disturbance agent, e.g. bark beetle infestation. We can accurately map forest mortality (see Question 2 below), and insofar as percent mortality and the basal area of dead trees correlates strongly with woody debris (i.e., surface fuel loads) and dead canopy (canopy fuel loads), we expect to be able to develop linear relationships between satellite-derived disturbance measures and field data on fuel loads. For example, we predicted the mass of coarse wood in ice-stormdamaged forests of the eastern US using the remote sensing Disturbance Index (DI) of Healey et al. (2005) with an $R^{2}=0.65$. We are mapping fuel loads for GYE forests using linear regression between field-measured fuels (sampled by Simard et al. in 2006-2007 in lodgepole pine, and sampled in 2010 for Douglas-fir stands) and remote sensing change detection indices $(\Delta \mathrm{DI}) . \Delta \mathrm{DI}$ is calculated as the difference between the DI from a summer Landsat image for a non-disturbance year (e.g., 1999 for the GYE) and the disturbance year, which would be our year of measurement (2006 or 2007 for lodgepole pine, or 2010 for Douglas-fir). Landsat images covering the entire study region are already on-hand for 1999-2010. Our experience with these disturbance indices is that relationships between field measures and the remote sensing data are robust among disturbances in different years (de Beurs and Townsend 2008), suggesting that we can apply the predictive relationships to years in which fuel loads were not measured. We are stratifying by forest type to determine whether the relationship between fuel loads and remote imagery varies between lodgepole pine and Douglas-fir, but our current analyses of beetle kill indicate that the statistical relationship between percent mortality and remote sensing data does not differ significantly by forest type (Simard et al. in prep).

Question 2. Field studies were initiated in the New Fork Lakes Fire, which burned $\sim 6,100$ ha in beetle-killed lodgepole pine on the BTNF during summer 2008; Figure 1). Using the maps of beetle kill for the GYE derived from remote sensing (described below) and field reconnaissance, our approach is to locate areas of heterogeneous pre-fire beetle severity within each fire. We established 100 sampling points within the New Fork Lakes Fire. Fire severity was evaluated at each point using 30-m diameter, which were designed specifically for studies incorporating remote sensing. We also measured pre-fire stand density, basal area, severity of bark beetle attack and fire, and regeneration, as we have done in previous post-fire studies (e.g., Turner et al. 1997, 1999).

From our previous research, we have developed a method to map the extent and severity of the bark beetle infestation in the GYE using a yearly time series (1999-2007) of 30-m Landsat imagery (Simard et al, in prep). Using late-summer, approximate anniversary date Landsat imagery for each year, we calculate a $z$-score for the difference in a vegetation index (the Moisture Stress Index, MSI; Rock et al. 1986) between a base non-disturbance date (1999) and a disturbance date, then interpret differences between images as the biomass change between time steps. We observe for bark beetles in the GYE that the remote sensing data correlate closely with field measures of infestation quantified as percent dead basal area $\left(R^{2}=0.77\right)$. This enables us to develop measures of percent mortality from which we can estimate not just the spatial extent and onset of beetle damage, but more importantly (and to our knowledge, for the first time for bark beetle outbreak), the local severity of the damage from the infestation. We are using our existing methods to characterize and update ongoing beetle-induced mortality for 2008-2010 for this project.

Question 3. We measured both soil temperature and ecosystem $\mathrm{N}$ pools and fluxes across a time-since-beetle chronosequence with four classes: undisturbed, red stage (2 years after attack), gray stage (4 years after attack), and older outbreak (30 years after attack). Vegetation and beetle activity surveys are described in Question 1. To assess how beetle disturbance redistributes $\mathrm{N}$ among ecosystem pools, litter and soil $\mathrm{N}$ samples were collected from $10,0.25 \mathrm{~m}^{2}$ microplots within $5 \mathrm{~m}$ radius plots $(N=5$ per class) at the center of each 0.25 ha stand (see Q1). Foliar $\mathrm{N}$ was collected from 3 unattacked trees per 
plot and pooled for analyses. Soil temperatures were measured using iButton probes (Maxim Integrated Products Inc., Dallas Semiconductor, Sunnyvale, CA) at three locations per plot). All chemical analyses of soil and plant $\mathrm{N}$ were conducted at the University of Wisconsin in the Soil and Plant Analysis Lab and the Center for Limnology. ANOVA tests were used to test for differences among classes, while Pearson correlation and linear regression analyses were performed to test relationships among ecosystem variables (Griffin et al. 2011).

\section{$\uparrow \quad$ PRELIMINARY ReSUlts}

Questions 1 and 2. Analysis of the field data collected during summer 2010 is ongoing.

Question 3. Bark beetle disturbance significantly altered $\mathrm{N}$ cycling through the litter, soil, and vegetation of lodgepole pine forests. Beetleinduced litterfall increased litter depth and litter $\mathrm{N}$ content, and cooled soil temperatures. Soil inorganic $\mathrm{N}$ pools and fluxes approximately doubled in recently disturbed stands compared to undisturbed stands. Increased soil $\mathrm{N}$ in recently disturbed stands was more closely related to cooler soil temperatures than to litter quality, and was positively correlated with increased fresh foliar $\mathrm{N}$ in unattacked vegetation which increased from 0.82 to $1.05 \% \mathrm{~N}$. Effects of bark beetle disturbance on litter chemistry, soil microclimate, and canopy $\mathrm{N}$ pool size persisted 30 years following outbreak. However, changes in soil $\mathrm{N}$ cycling were of lesser magnitude than those observed following stand replacing fire, and several lines of evidence suggest that $\mathrm{N}$ limitation may still be important in beetle-killed forests and that the potential for $\mathrm{N}$ leaching is low following bark beetle disturbance in lodgepole pine. Full results from Question 3 can be found in Griffin et al (2011).

\section{$\uparrow \quad$ ACKNOWLEDGEMENTS}

This research was funded by the Joint Fire Science Program (JFSP) and the Western Wildland Environmental Threats and Assessment Center (WWETAC) of the US Forest Service and facilitated by Roy Renkin (Yellowstone National Park) and Diane Abendroth (Grand Teton National Park), as well as the Bridger-Teton and Shoshone National Forests. We appreciate the opportunity to use lodging and laboratory facilities at the UW-NPS Research Station.

\section{LITERATURE CITED}

Brown JK. 1974. Handbook for inventorying downed woody material. Gen. Tech. Rep. INT-16, USDA For. Serv., Interm. For. Rang. Exp. Stn, Ogden, UT.

Brown JK. 1978. Weight and density of crowns of Rocky Mountain conifers. Res. Pap. INT197, USDA For. Serv. Interm. For. Range Exp. Stn, Ogden, UT.

De Beurs KM, Townsend PA. 2008. Estimating the effect of gypsy moth defoliation using MODIS. Remote Sens. Environ. 112:39833990.

Griffin JM, Turner MG, Simard M. 2011. Nitrogen cycling following mountain pine beetle disturbance in lodgepole pine forests of Greater Yellowstone. Forest Ecology and Management 261:1077-1089.

Healey SP, Cohen WB, Yang ZQ, Krankina ON. 2005. Comparison of Tasseled Cap-based Landsat data structures for use in forest disturbance detection. Remote Sens. Environ. 97:301-310.

Huber C. 2005. Long lasting nitrate leaching after bark beetle attack in the highlands of the Bavarian Forest National Park. J. Environ. Qual. 34, 1772-1779

Jenkins MJ, Hebertson E, Page WG, Jorgensen CA. 2008. Bark beetles, fuels, fires and implications for forest management in the Intermountain West. Forest Ecol. Manage. 254:16-34.

Keane RE. 2008. Biophysical controls on surface fuel litterfall and decomposition in the northern Rocky Mountains, USA. Can. J. Forest Res. 38: 1431-1445.

Keane RE, Frescino T, Reeves M. Long, J. 2006. Chapter 12. Mapping wildland fuel across large regions for the LANDFIRE Prototype Project. In; Rollins M, Frame C. editors. The LANDFIRE Prototype Project: nationally consistent and locally relevant geospatial data for wildland fire management. Gen. Tech. Rep. RMRS-GTR-175, USDA For. Serv., Rocky Mtn. Res. Stn, Fort Collins, CO. 
Lynch HJ, Renkin RA, Crabtree RL, Moorcroft PR. 2006. The influence of previous mountain pine beetle Dendroctonus ponderosae) activity on the 1988 Yellowstone fires. Ecosystems 9:1318-1327.

Miller JD, Thode AE. 2007. Quantifying burn severity in a heterogeneous landscape with a relative version of the delta Normalized Burn Ratio (dNBR). Remote Sens. Environ. 109:66-80.

Morehouse K, Johns T, Kaye J, Kaye A. 2008. Carbon and nitrogen cycling immediately following bark beetle outbreaks in southwestern ponderosa pine forests. For. Ecol. Manage. 255:2698-2708.

Negron JF, Bentz BJ, Fettig CJ and others. 2008. US Forest Service bark beetle research in the western United State: looking toward the future. J. Forestry (Sept 2008):325-331

Page WG, Jenkins MJ. 2007a. Mountain pine beetleinduced changes to selected lodgepole pine fuel complexes within the intermountain region. Forest Sci. 53:507-518.

Page WG, Jenkins MJ. 2007b. Predicted fire behavior in selected Mountain pine beetle-infested lodgepole pine. Forest Sci. 53:662-674.

Raffa KF, Aukema BH, Bentz BJ, Carroll AL, Hicke JA, Turner MG, Romme WH. 2008. Crossscale drivers of natural disturbances prone to anthropogenic amplification: the dynamics of bark beetle eruptions. BioScience 58:501517.

Rock BN, Vogelmann JE, Williams DL, Vogelmann AF Hoshizaki T. 1986. Remote detection of forest damage. BioScience 36: 439-445.

Scott JH, Reinhardt ED. 2001. Assessing crown fire potential by linking models of surface and crown behavior. Res. Pap. RMRS-RP-29, USDA For. Serv., Rocky Mtn Res. Stn, Ogden, UT.
Simard M, Powell EN, Griffin JM, Raffa KF, Turner MG. 2008. Annotated bibliography for forest managers on fire-bark beetle interactions. US Forest Service, Western Wildlands Environmental Threats Assessment Center. http://www.fs.fed.us/ wwetac/publications.html.

Simard M, Turner MG, Griffin JM, Romme WH. 2011. Do mountain pine beetle outbreaks change the probability of active crown fire in lodgepole pine forests? Ecological Monogr.

Simard M, Jin S, Townsend PA. In prep. Detection of the timing and intensity of mountain pine beetle infestation in the Greater Yellowstone Ecosystem using a 1999-2007 Landsat time series. For submission to Remote Sens. Environ.

Turner MG, Romme WH, Gardner RH. 1999. Prefire heterogeneity, fire severity, and early postfire plant reestablishment in subalpine forests of Yellowstone National Park, Wyoming. Int. J. Wildland Fire 9:21-36.

Turner MG, Romme WH, Gardner RH, Hargrove W W. 1997. Effects of fire size and pattern on early succession in Yellowstone National Park. Ecol. Monogr. 67:411-433.

Westerling AL, Hidalgo HG, Cayan DR, Swetnam, TW. 2006. Warming and earlier spring increase western U.S. forest wildfire activity. Science 313:940-943.

Wulder MA, White JC, Bentz B, Alvarez F, Coops N. 2006. Estimating the probability of mountain pine beetle red attack damage. Remote Sens. Environ. 101:150 